\title{
In Vitro Osteogenic Induction Of Human Gingival Fibroblasts For Bone Regeneration
}

\author{
Nesrine Z. Mostafa ${ }^{1}$, Hasan Uludağ $\breve{g}^{2,3,4}$, Mathew Varkey ${ }^{5}$, Douglas N. Dederich ${ }^{1}$, Michael R. \\ Doschak $^{2,4}$ and Tarek H. El-Bialy ${ }^{1,2, *}$.
}

\author{
${ }^{I}$ Department of Dentistry, Faculty of Medicine and Dentistry, University of Alberta, Edmonton, AB, Canada \\ ${ }^{2}$ Department of Biomedical Engineering, Faculty of Medicine and Dentistry, University of Alberta, Edmonton, AB, \\ Canada \\ ${ }^{3}$ Department of Chemical and Materials Engineering, Faculty of Engineering, University of Alberta, Edmonton, AB, \\ Canada \\ ${ }^{4}$ Faculty of Pharmacy and Pharmaceutical Sciences, University of Alberta, Edmonton, AB, Canada \\ ${ }^{5}$ Department of Surgery, Faculty of Medicine and Dentistry, Wound Healing Research Group, University of Alberta, \\ Edmonton, AB Canada
}

\begin{abstract}
Background And Objective: Periodontitis is an inflammatory disease causing bone loss, and is a primary cause of tooth loss. Gingival fibroblasts are readily available with minimal donor site morbidity and may be ideal for tissue engineering efforts in regenerating lost alveolar bone. Dexamethasone (Dex) is commonly employed for in vitro osteogenic induction of a variety of cells, but its effect on human gingival fibroblasts (HGF) is still controversial. Therefore, the aim of our study was to investigate the osteogenic differentiation of HGF following Dex treatment.

Methods: Cultured HGFs were exposed to osteogenic medium containing a wide range of Dex concentrations (0.01-10 $\mu \mathrm{M}$ ). The osteogenic phenotype was assessed based on changes in alkaline phosphatase (ALP) activity, the mRNA expression of selected extracellular matrix proteins critical for mineralization and the extent of extracellular mineralization (Von Kossa staining and Ca-content).

Results: All assays showed a consistent and maximal osteogenic effect of Dex on HGF at 0.1 and $0.5 \mu \mathrm{M}$ (weeks 3 and 4), as evidenced by significant osteopontin and osteocalcin expression and mineralization. Longer cultures (week 4) also yielded positive osteogenic effect of Dex at $0.01 \mu \mathrm{M}$. Moreover, ALP activity was significantly stimulated at 0.1 and 0.5 $\mu \mathrm{M}$ Dex initially after one week, but ALP was subsequently reduced under Dex. Higher Dex concentrations caused down regulation of osteogenic effects observed at the optimal $(0.1-0.5 \mu \mathrm{M})$ concentrations.

Conclusion: Under appropriate osteogenic conditioning, Dex treated HGFs could be a potential source of cells for cell-based therapy for periodontal bone regeneration.
\end{abstract}

Keywords: Periodontitis, gingival fibroblasts, dexamethasone, osteogenic differentiation, bone regeneration.

\section{INTRODUCTION}

Periodontal diseases results in irreversible loss of alveolar bone [1]. The loss of supporting bone around roots can be partially remedied using various grafting materials, with autologous grafts being the most successful among them [2]. Guided tissue regeneration is another approach that can be used in regeneration of lost alveolar bone [3]. Nonetheless, the success of both techniques is based on different systemic and local factors including: defect type, age, genetics, and disease predisposition $[2,3]$. To overcome the limitations related to the current treatments, bone tissue engineering

*Address correspondence to this author at the University of Alberta, Department of Dentistry Room 4051C, Dentistry/Pharmacy Centre Edmonton, Alberta, Canada T6G 2N8; Tel: 780-492-2751; Fax: 780-492-1624;

E-mail: telbialy@ualberta.ca including cell-based therapy has been proposed as an alternative therapeutic solution for periodontal disease [4]. That approach, however, is often hampered by the need for large quantities of tissue-specific cells when the cell-based approach is considered.

Gingival fibroblasts (GF) and periodontal ligament (PDL) cells form the major cellular components of the periodontal connective tissue and are responsible for extracellular matrix production [5]. It has been hypothesized that PDL cells may differentiate into osteoblast-like cells during periodontal regeneration and may contribute to alveolar bone formation [6]. The localization of mRNA transcripts traditionally associated with mineralized tissue such as ALP, osteopontin (OPN), and osteocalcin (OCN) were stronger in PDL compared to gingival tissue [7, 8]. Accordingly, the PDL has been considered a promising source of cells for regenerating alveolar bone, due to their proven osteogenic 
differentiation potential [9]. On the other hand, GF cells are more accessible with significantly less donor-site morbidity compared to PDL cells, which necessitates tooth extraction for harvesting. Thus, GF might be a more suitable cell type that might be used for periodontal regeneration, but their ability to differentiate into an osteogenic phenotype had not been fully established.

The successful use of GF for alveolar bone regeneration would require those cells to be differentiated into an osteogenic pathway before transplantation. Osteogenesis in pluripotent cells can be achieved using growth factors, such as Bone Morphogenetic Proteins (BMPs) or hormones such as Dexamethasone (Dex) [10]. The latter is a more acceptable agent for the in vitro induction of osteogenesis, given its low cost and stability in the physiological environment. Dex is a synthetic glucocorticoid, that has an anti-inflammatory and immunosuppressant effect in vivo [11]. Dex is often used for in vitro osteogenic induction of bone marrow cells in combination with ascorbic acid and ß-glycerolphosphate [10], as it mediates ALP synthesis and activity in osteoblasts [12]. In previous studies, Dex has been used for in vitro osteogenic differentiation and mineralized matrix formation in human PDL cells, but its effect on HGF remains unclear [1315]. Dex was shown to up-regulate osteogenic biomarkers in HGF in one report [15], but not others [13, 14]. No consistent effect of Dex on HGF has been reported, however, only limited concentrations or single dosages were studied in those reports [13-15]. Accordingly, it can be hypothesized that the concentration of Dex used to potentially induce osteogenic differentiation of HGF could be expected to play a significant role in those studies.

Thus, we examined the osteogenic potential of Dex on HGF cells to determine its utility for cell-based bone regenerative therapies, such as alveolar bone regeneration. In the current study, we evaluated the effect of osteogenic media containing a wide range of Dex concentrations to elicit HGF osteogenic differentiation and mineralization in vitro.

\section{MATERIALS AND METHODS}

\section{Materials}

Dulbecco's Modified Eagle Medium (DMEM), penicillin/streptomycin (10,000 U/mL/10,000 $\mu \mathrm{g} / \mathrm{mL}$ solutions), fetal bovine serum (FBS) and Hank's Balanced Salt Solution (HBSS) were from GIBCO (Grand Island, NY). The CyQUANT cell proliferation kit from Molecular Probes (Portland, OR) was used to quantify the DNA concentrations in HGF cell lysates. Hexosaminidase substrate p-nitrophenol glucoseaminide, ALP substrate p-nitrophenol phosphate (pNPP), 3-(4,5-dimethylthiazol-2-yl)-2,5-diphenyltetrazolium bromide (MTT), Dex, $\beta$-glycerophophate (B-GP), and ascorbic acid were obtained from Sigma (St. Louis, MO).

\section{Isolation and Culture of Gingival Fibroblasts}

The HGF cell line was established from gingival biopsies that were obtained from healthy interdental papilla and placed in a 'biopsy' medium, containing DMEM with 100 $\mathrm{U} / \mathrm{mL}$ penicillin, and $100 \mu \mathrm{g} / \mathrm{mL}$ streptomycin. Informed consent was obtained from all donors and the research protocol was approved by our University Health Research Ethics Board. Gingival tissues, were diced into small pieces, seeded onto glass slides in cell culture plates, and incubated with basic medium (DMEM, 10\% FBS, $100 \mathrm{U} / \mathrm{mL}$ penicillin, and $100 \mu \mathrm{g} / \mathrm{mL}$ of streptomycin) at $37^{\circ} \mathrm{C}$ in a humidified atmosphere of $5 \% \mathrm{CO}_{2}$. When cellular outgrowth from the gingival explants was confluent following 2-3 weeks of culture, they were transferred to $75 \mathrm{~cm}^{2}$ tissue culture flasks using $0.08 \%$ trypsin $/ 0.04 \%$ ethylenediamine-tetraacetic acid.

\section{Osteogenic Treatment with Dex}

HGFs at passage 4 were grown in 48 well plates at an initial seeding density of $2.5 \times 10^{3}$ cells/well. The experimental groups were treated with osteogenic media containing basic medium, with the addition of $10 \mathrm{mM} \mathrm{B-GP}$ and $50 \mu \mathrm{g} / \mathrm{ml}$ ascorbic acid to stimulate mineralization. Cells were then divided into five subgroups based on the Dex concentration used $(0.01,0.1,0.5,1.0$ and $10 \mu \mathrm{M})$. The control group was treated with basic medium alone. Cell culture medium was changed 2 times per week. After different periods of incubation (weeks 1, 2, 3, and 4), replicates of HGF cultures were analyzed for cell viability (MTT), proliferation (growth curve and DNA assay), differentiation (ALP activity and gene expression analysis of select bone extracellular matrix proteins), and calcified matrix synthesis (Von Kossa staining and quantification of $\mathrm{Ca}$-content).

\section{MTT Assay for Cell Viability}

The MTT assay is based on the conversion of a tetrazolium salt (MTT) into a blue formazan in the viable cells. Briefly, MTT was dissolved in HBSS $(5 \mathrm{mg} / \mathrm{mL})$ and a 100 $\mu \mathrm{L}$ of MTT solution was added into each well containing 0.5 $\mathrm{mL}$ medium in 48-well plates. After 2 hours of incubation, the medium was replaced with $500 \mu \mathrm{L}$ of dimethylsulfoxide to dissolve the formed formazan crystals. The absorbance of the colored solution was quantified at $570 \mathrm{~nm}$ [16].

\section{Hexosaminidase Assay for Cell Growth}

Changes in cell number were determined to evaluate HGF cell growth as a function of Dex concentration in osteogenic supplements. In brief, $0.15 \mathrm{mM}$ p-nitrophenol glucoseaminide was dissolved in $0.1 \mathrm{M}$ citrate buffer $(\mathrm{pH} 5.0)$ and mixed with an equal volume of $0.5 \%$ Triton $\mathrm{X}-100$ in water. Then, $100 \mu \mathrm{L}$ of the substrate solution was added to HGF cells into 96-well plates. After 4 hours of incubation, enzymatic activity was blocked by the adding $50 \mathrm{mM}$ glycine buffer containing $5 \mathrm{mM}$ Ethylenediaminetetraacetic acid and absorbance was quantified at $405 \mathrm{~nm}$. Different cell concentrations were used to generate a standard curve which was used to calculate the cell number per well at each time point. Changes in cell number were fitted using GraphPad Prism 5 software (GraphPad Software, Inc., La Jolla, CA), where the normal logarithm of cell number against time resulted in straight line through the exponential growth phase. The slope of this line was calculated in order to get the maximum specific growth rate [16].

\section{Specific ALP Assay}

As ALP activity is critical for calcification [17], the effect of osteogenic supplements on the ALP activity of HGF was quantified. Cultured HGF were washed with HBSS and lysed using ALP buffer containing $0.5 \mathrm{M}$ 2-amino-2methylpropan-1-ol and $0.1 \%(\mathrm{v} / \mathrm{v})$ Triton-X100 at $\mathrm{pH} 10.5$. 
After two hours, $100 \mu \mathrm{L}$ from each lysate was added in duplicates into 96 -well plates and a $100 \mu \mathrm{L}$ of $2 \mathrm{mg} / \mathrm{mL}$ ALP substrate p-NPP was added to the cell lysate. The absorbance of the colored product was then quantified at $405 \mathrm{~nm}$ at periodic intervals for up to 20 minutes. The ALP activity was presented as p-NPP formed for every minute $(\mathrm{mmol} / \mathrm{min} / \mathrm{mL})$, and normalized by the total DNA content $(\mu \mathrm{g} \mathrm{DNA} / \mathrm{mL})$ of each lysate to attain the specific ALP activity (ALP/DNA). DNA concentrations were determined using the CyQUANT DNA kit in accordance with the manufacturer's instructions [16].

\section{Reverse Transcription Polymerase Chain Reaction (RT-PCR) Analyses}

HGF were harvested at week 3 and week 4 with Trizol $^{\circledR}$ Reagent and stored at $-20^{\circ} \mathrm{C}$. Extraction of RNA was performed using the RNeasy Mini Kit and according to the manufacturer's guidelines. Then, total RNA content was fluorometrically quantified at $\lambda$ excitation: $480 \mathrm{~nm}$ and $\lambda$ emission: $527 \mathrm{~nm}$ with the SYBR Green dye. Subsequently, $0.3 \mu \mathrm{g}$ of the extracted RNA were consumed for the reverse transcription (RT) reaction using the Omniscript kit. Finally, the resulting cDNA was used as a template for the Polymerase Chain Reaction (PCR) amplification for the genes of interest, namely; OPN, OCN, with the housekeeping gene glyceraldehyde-3-phosphate dehydrogenase (GAPDH) used as the internal control. Specific oligonucleotide primer sequences were obtained from the literature, and synthesized as follows:

\section{GAPDH (158 bp; [18]) Forward: 5': CTGAACGGGAAGC- TCACTGG-3'}

Reverse: 5': TAGCCCAGGATGCCCTTGAG-3'

OPN (126 bp; [19]) Forward: 5': CCAAGTAAGTCCAACGAAAG -3

Reverse: 5': GGTGATGTCCTCGTCTGTA -3'

OCN (315 bp; [19]) Forward: 5': GGCAGCGAGGTAGTGAAGA-3

Reverse: 5': CTGGAGAGGAGCAGAACTG-3'

The PCR conditions employed for all primers were as follow: denaturation $\left(95^{\circ} \mathrm{C}\right.$ for $\left.1 \mathrm{~min}\right)$, annealing $\left(58^{\circ} \mathrm{C}\right.$ for 1 $\mathrm{min})$, and extension $\left(72^{\circ} \mathrm{C}\right.$ for $\left.1 \mathrm{~min}\right)$, with 35 cycles of amplification. The relative gene-expression was quantified using densitometry of the respective PCR products (OPN 126 bp, OCN 315 bp, and GAPDH 158 bp). Alpha Innotech bioimaging system (Alpha Innotech Corp., San Leandro, CA) were utilized to photograph ethidium bromide-stained $2 \%$ agarose gels. Finally, the densitometry values obtained for OCN, OPN, and BSP were normalized with GAPDH densitometry value, which are presented in Fig. (4B and $\mathbf{C}$ ).

\section{Von Kossa Staining}

HGF treated with or without osteogenic media were rinsed with cold PBS after week 3 and week 4, and fixed in $10 \%$ formalin for 30 minutes at room temperature. The cells were then rinsed twice with distilled water and incubated in
$2 \%$ silver nitrate in the dark for 10 minutes. The silver nitrate solution was rinsed away 3 times with distilled water, exposed to bright light for 15 minutes, and dehydrated in $100 \%$ ethanol. Calcified extracellular matrix was stained brownblack [20].

\section{Calcium Assay}

Wells containing HGF lysates from the ALP Assay were washed twice with HBSS and $0.5 \mathrm{~mL}$ of $\mathrm{HCl}(0.5 \mathrm{M})$ was added overnight to dissolve the formed mineral. Samples were then stored at $4{ }^{\circ} \mathrm{C}$ until analysis. Aliquots $(20 \mu \mathrm{l})$ of each sample were added to $50 \mu \mathrm{L}$ of a solution containing $0.028 \mathrm{M} 8$ 8-hydroxyquinoline and $0.5 \%(\mathrm{v} / \mathrm{v})$ sulfuric acid, plus $0.5 \mathrm{~mL}$ of a solution containing $3.7 \times 10^{-4} \mathrm{M} \mathrm{o-}$ cresolphthalein and 1.5\% (v/v) AMP (2-amino-2-methylpropan-1-ol). The absorbance was measured spectrophotometrically at $570 \mathrm{~nm}$. Calcium standards was utilized to generate the standard curve and to calculate calcium concentration in each sample which was expressed in terms of $\mathrm{mg} / \mathrm{dL}[21]$.

\section{Statistical Analysis}

All assays were performed in triplicate for each treatment at each time point and the results were expressed as mean \pm standard deviation (SD). Data were analyzed with one-way analysis of variance (ANOVA) using SPSS version 12.0 software package (SPSS, Chicago, IL, USA). Intergroup differences were determined using the Boneferroni post-hoc test, and statistical significance was defined by p-values $<$ 0.05 .

\section{RESULTS}

\section{Cell Viability and Growth}

The MTT assay showed a gradual increase in cell viability during the 4 week study period, in particular between week 2 and week 3 (Fig. 1). There was no effect of Dex on cell viability when Dex concentration was varied from 0.01 to $10 \mu \mathrm{M}$.

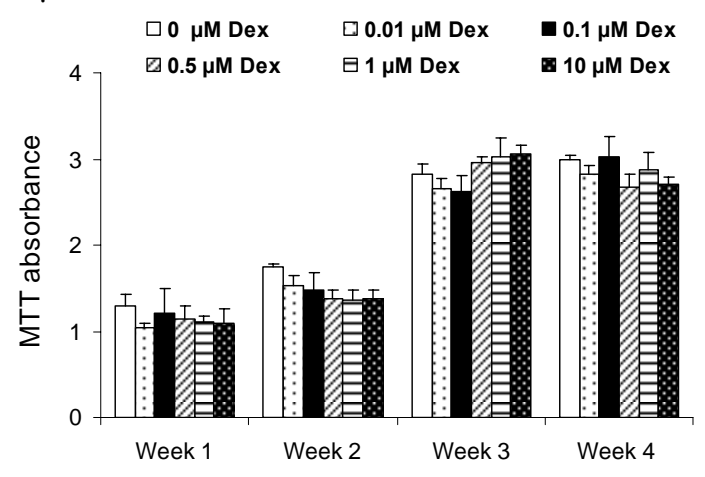

Fig. (1). Effect of Dex concentration on cell viability as measured by the MTT assay after weeks 1,2,3, and 4 . Each point represents mean \pm SD of triplicate wells. There was no effect of Dex on HGF cell viability at any time point.

Based on the hexosaminidase assay, changes in HGF cell number as function of time are summarized in Fig. (2). Sigmoid growth curves consisting of a lag phase (approximately up to day 4), exponential growth phase (approximately day 5 to day 10) and stationary phase (after day 10) were evident 




Fig. (2). Effect of Dex concentration on HGF cell growth rate. Each point represents the mean from six wells at each time point. There was no apparent effect of Dex on the cell growth pattern.

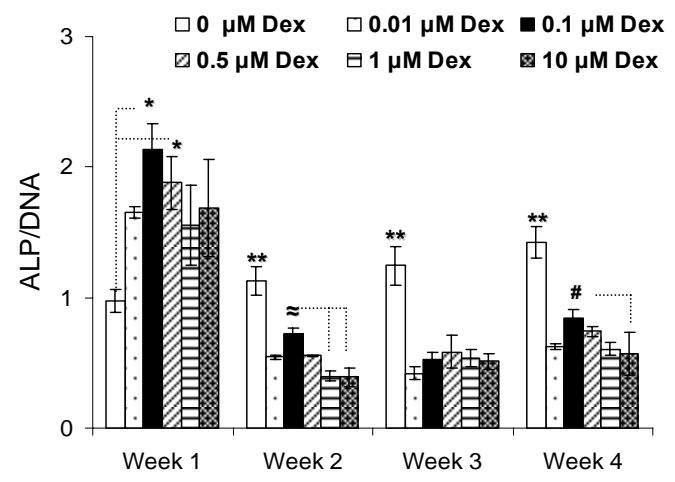

Fig. (3). Effect of Dex concentration on the cellular specific ALP activity (ALP/DNA) after 1, 2, 3, and 4 weeks. Each bar represents the mean \pm SD of triplicate wells. Dex at 0.1 and $0.5 \mu \mathrm{M}$ stimulated ALP activity in the first week $\left(^{*}: \mathrm{p}<0.01\right.$ as compared to $0 \mu \mathrm{M}$ Dex), but subsequent ALP was reduced in the presence of Dex. $(* *$ : $\mathrm{p}<0.001$ as compared to $0 \mu \mathrm{M}$ Dex). Dex at $0.1 \mu \mathrm{M}$ maintained higher ALP at week $3(\approx: \mathrm{p}<0.05$ as compared to 1 and $10 \mu \mathrm{M}$ Dex $)$ and week 4 (\#: $<<0.05$ as compared to $10 \mu \mathrm{M}$ Dex).

for all study groups. All Dex concentrations tested gave a similar lag phase as compared to the control group $(0 \mu \mathrm{M}$
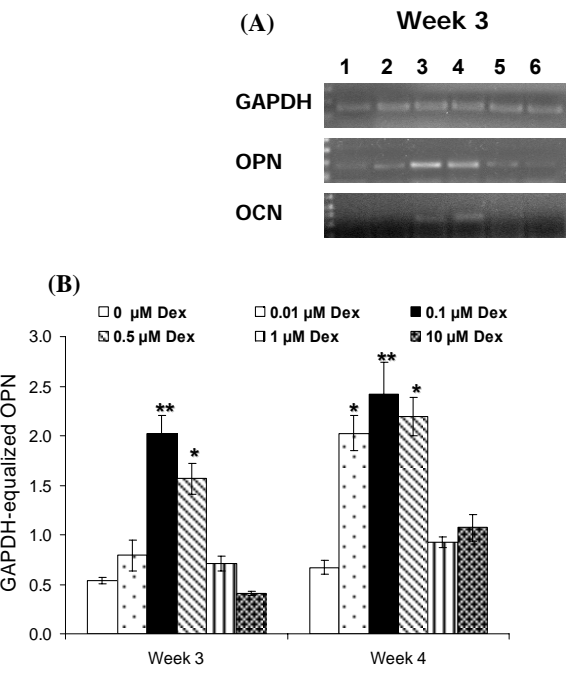

Dex). The growth rates of HGF treated with increasing Dex concentration were also similar; the doubling times were 17, $14.5,16,13,16$, and 15 hours when Dex concentrations were $0,0.01,0.1,0.5,1$, and $10 \mu \mathrm{M}$, respectively. The final cell numbers attained were also similar in all study groups.

\section{Specific ALP Activity}

The specific ALP activity in control HGF cells was initially (week 1) lower than the HGF cells treated with Dex, where differences were significantly increased for the 0.1 and $0.5 \mu \mathrm{M}$ Dex concentration $(\mathrm{p}<0.01$, Fig. 3). At weeks 2, 3 and 4, the specific ALP activity of HGF in all Dex treatment groups were statistically decreased compared to the untreated control cells $(\mathrm{p}<0.001)$. For Dex treated HGF cells, the specific ALP activity was measured to be the highest in the $0.1 \mu \mathrm{M}$ Dex concentration group, reaching statistically significant levels on week $2(\mathrm{p}<0.01$ as compared to 1 and 10 $\mu \mathrm{M}$ Dex) and week 4 ( $\mathrm{p}<0.05$ as compared to $10 \mu \mathrm{M}$ Dex $)$.

\section{Expression of OPN and OCN by HGF}

The results of RT-PCR analysis for the expression of OPN and OCN are summarized in Fig. (4). The HGF cells treated with Dex demonstrated significant up-regulation of both OPN (Fig. 4B) and OCN (Fig. 4C). The expressions of OPN and OCN were similar; Dex concentrations of $0.1 \mu \mathrm{M}$ and $0.5 \mu \mathrm{M}$ stimulated OPN and OCN expression by week 3 $(\mathrm{p}<0.001$ and $\mathrm{p}<0.01$ respectively as compared to other treatment groups). Dex concentrations of $0.01 \mu \mathrm{M}, 0.1 \mu \mathrm{M}$ and $0.5 \mu \mathrm{M}$ stimulated OPN and OCN expression by week 4 $(\mathrm{p}<0.01$ as compared to 0,1 and $10 \mu \mathrm{M}$ Dex). However, further increases in Dex concentration did not increase OPN and $\mathrm{OCN}$ expression for any time point.

\section{Von Kossa Staining and Calcification}

HGF cells stimulated with Dex concentrations of 0.1 $\mu \mathrm{M}$ and $0.5 \mu \mathrm{M}$ Dex stained positively for calcification after 3 and 4 weeks of culture (Fig. 5). While cells treated with

Week 4

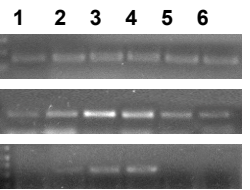

(C)

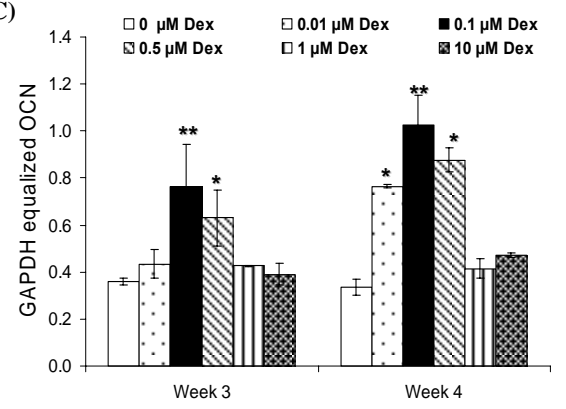

Fig. (4). A. Effect of Dex concentration on the cellular mRNA expression of OPN and OCN by HGF cells after 3 and 4 weeks. (1) $0 \mu \mathrm{M}$ Dex, (2) $0.01 \mu \mathrm{M}$ Dex, (3) $0.1 \mu \mathrm{M}$ Dex, (4) $0.5 \mu \mathrm{M}$ Dex, (5) $1 \mu \mathrm{M}$ Dex and (6) $10 \mu \mathrm{M}$ Dex. RT-PCR bands from a representative well for each sample is shown. B and C. Densitometric analyses of OPN and OCN mRNA expression at week 3 and 4 after normalization with GAPDH. Results represent average \pm SD of triplicate wells at each time point. Dex concentrations of 0.1 and $0.5 \mu \mathrm{M}$ stimulated OPN and OCN expression by week $3(* *: \mathrm{p}<0.001$ and $*: \mathrm{p}<0.01$ as compared to other treatment groups). Dex concentrations of $0.01,0.1$ and $0.5 \mu \mathrm{M}$ stimulated OPN and OCN expression by week $4\left(*: \mathrm{p}<0.01\right.$ and ${ }^{* *}: \mathrm{p}<0.001$ as compared to 0,1 and $10 \mu \mathrm{M}$ Dex). 
Week 3


Week 4
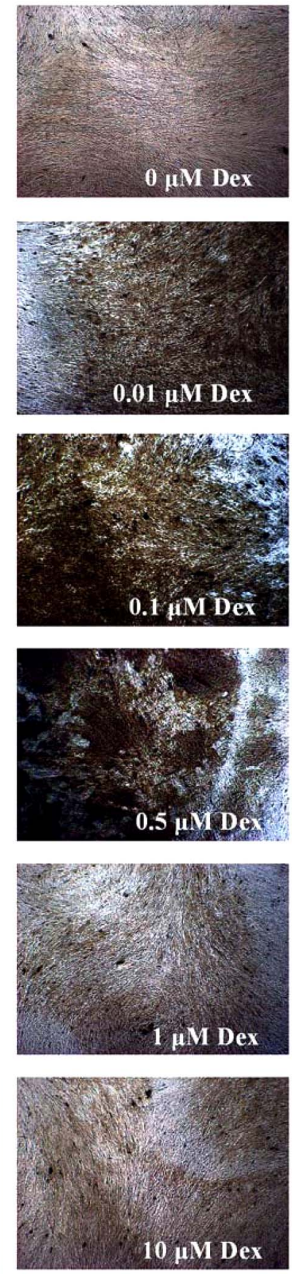

Fig. (5). Von Kossa staining of HGF cells after 3 and 4 weeks of osteogenic treatments. Note the higher calcification of HGF cultures treated with 0.01 (week 4), 0.1 (week 3 and 4) and $0.5 \mu \mathrm{M}$ Dex (week 3 and 4).

$0.01 \mu \mathrm{M}$ Dex did not stain positively for calcification on week 3, longer cultures (week 4) yielded positive staining for those cells. Treatments with higher Dex concentrations (1 and $10 \mu \mathrm{M})$ did not yield any calcification, as evidenced by the Von Kossa staining.

Based on the spectroscopic calcium assay, the extent of calcification was significantly increased in HGF treated with 0.1 and $0.5 \mu \mathrm{M}$ Dex $(\mathrm{p}<0.001)$ as compared to the other groups at week 3 (Fig. 6). By week 4, the extent of calcification was highest with osteogenic media containing $0.1 \mu \mathrm{M}$ Dex ( $\mathrm{p}<0.05$ compared to $0.01 \mu \mathrm{M}$ and $0.5 \mu \mathrm{M}$ Dex concentrations and $p<0.001$ as compared to other groups), followed by $0.01 \mu \mathrm{M}$ and $0.5 \mu \mathrm{M}$ Dex groups $(\mathrm{p}<0.01)$. This pattern was consistent with the Von Kossa staining results.

\section{DISCUSSION AND CONCLUSIONS}

Periodontal therapies aim to restore the lost alveolar bone. The fibroblasts are responsible for connective tissue matrix synthesis and have essential roles in the development, regeneration and function of the tooth supporting apparatus [22]. Although the capacity for human PDL cells to differentiate into osteogenic linage (with subsequent mineralized

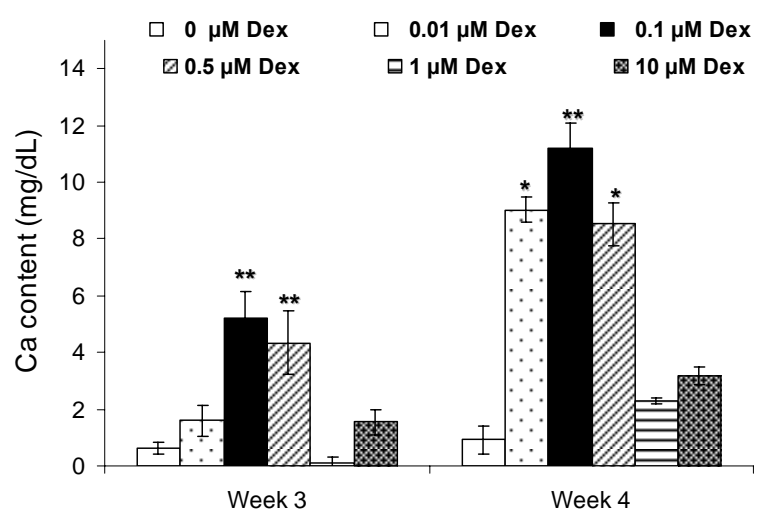

Fig. (6). Effect of Dex concentration on calcification of HGF cells after 3 and 4 weeks. Each bar represents the mean \pm SD of triplicate wells. Significant mineralization was present for 0.1 and $0.5 \mu \mathrm{M}$ Dex at week $3(* *$ : p $<0.001$ as compared to other groups) and 0.01 , 0.1 and $0.5 \mu \mathrm{M}$ Dex at week $4(* *: \mathrm{p}<0.001$ and $*$ : $\mathrm{p}<0.01$ as compared to 0,1 and $10 \mu \mathrm{M}$ Dex).

tissue formation) has been reported, the osteogenic capacity of the anatomically adjacent HGF is still controversial [13$15]$. Two studies $[13,14]$ reported that osteogenic treatments containing $0.1 \mu \mathrm{M}$ Dex could induce osteogenic differentiation and in vitro mineralization in human PDL cells, but not in HGF. Similarly, another report [23] showed that treatment with $0.01 \mu \mathrm{M}$ Dex resulted in mineralization in human PDL cells, but not in HGF. However, another study [15] demonstrated the positive osteogenic induction of HGF with 0.01 $\mu \mathrm{M}$ Dex in $25 \%$ of HGF samples ( 3 out of 12 ), based on Von Kossa staining and OCN synthesis. Therefore, our study was undertaken to evaluate the in vitro changes in HGF for select osteogenic biomarkers following treatment with different Dex concentration between 0.01 and $10 \mu \mathrm{M}$.

Osteogenic treatment of HGF cells should exert little or no damage to the cells, ensuring their robust proliferation and differentiation to obtain a sufficient cell mass for therapy. In previous reports, $0.01 \mu \mathrm{M}[15]$ and $0.1 \mu \mathrm{M}$ Dex [13, 14] did not result in growth inhibition or toxicity, although a wider range of Dex concentrations was not been evaluated in those studies. We measured the viability (using the MTT Assay) of HGF treated with increasing concentrations of Dex. Dex did not affect HGF cell viability in either a timeor dose-dependent manner. This finding was also confirmed by the growth rates, which showed no significant changes when cells were treated with osteogenic supplement containing increasing Dex concentrations against the control group.

The osteogenic differentiation in HGF cultures was assessed based on specific ALP activity, mRNA expression for select extracellular matrix proteins (OPN and OCN), and extent of mineralization. ALP is an early marker for osteogenic differentiation that augment calcification through the hydrolysis of pyrophosphate and ATP, which inhibit calcification, and is crucial for phosphate production, needed for the crystallization of hydroxyapatite [17]. In our study, HGF exhibited a significant increase in the specific ALP activity after treatment with osteogenic supplements containing 0.1 and $0.5 \mu \mathrm{M}$ Dex compared to the untreated control group, initially after one week of culture. Subsequently, 
there was a significant reduction in the specific ALP activity with Dex treatment. Such reduction in the ALP activity might be due to decrease in the number of osteoprogenitor cells in the cultured HGF and suggesting early maturation of the osteogenic phenotype based on this biomarker. In contrast, untreated HGF maintained a basal level of ALP activity over the 28 day culture duration compared to Dex-treated HGF. These results are in agreement with Ivanovski et al. [8] who reported that HGF cells expressed ALP under normal culture condition without Dex stimulation.

OPN and OCN are indicators for early and late phase of osteogenic differentiation, respectively [14]. OCN is regarded as the most specific matrix protein produced by osteoblasts during the onset of matrix mineralization as it binds hydroxyapatite $[24,25]$. Ivanovski et al. [8] reported that OPN and OCN were not detected in HGF cultured in basic medium at early stages. Another study [26] treated HGF with osteogenic medium containing $50 \mu \mathrm{g} / \mathrm{ml}$ ascorbic acid, 10 $\mathrm{mM} \beta$-GP and $0.1 \mu \mathrm{M}$ Dex (similar to the osteogenic medium used in our study) and could not detect OPN expression in HGF at day 14. Therefore, we performed the RTPCR analysis on week 3 and 4 based on the available literature. The mRNA expression levels of both OPN and OCN were significantly increased with Dex treatment, with optimal effect observed at 0.1 and $0.5 \mu \mathrm{M}$ Dex. Whereas OPN and OCN were previously shown to be expressed at different stages of mineralization [27], our results indicated a similar expression pattern for the two proteins. We only investigated late stages of mineralization ( 3 and 4 weeks) and utilizing an earlier time point for RT-PCR analysis might reveal such differences. Consistent with the increased expression of OPN and OCN, the HGF cells underwent increased mineralization in those treatment groups. Our mineralization data were similar to the study by Zhou et al. [15] that demonstrated positive osteogenic induction of HGF with $0.01 \mu \mathrm{M}$ Dex in $25 \%$ of HGF samples (3 out of 12), based on Von Kossa staining and OCN synthesis. However, Arceo et al. [13] only reported mineralization of HGF cells treated with osteogenic supplements containing $0.1 \mu \mathrm{M}$ Dex for days 20 to 30 based on Von Kossa staining, although other markers such as ALP activity and OCN expression were not assessed in their study. Pi et al. [14], on the other hand, reported a dramatic increase in osteonectin expression by HGF cells but not OPN and BMP-2, after 14 days of osteogenic treatment containing $0.1 \mu \mathrm{M}$ Dex [14]. In addition, they did not demonstrate any increase in ALP activity or mineralization. It may be noted that in their study [14], the ALP activity was analyzed until day 7, osteogenic marker expression at only one time point (day 14), and mineralization only until day 21 . Our study was more thorough in that respect, but it is possible the differences between our results and those studies might also be related to the heterogeneity of human adult cells and the particular location of the harvested tissues. It is known that the characteristics of human cells induced for osteogenic differentiation vary depending on the anatomical site and the donor's age and gender [28]. For example, Carnes et al. [29] reported that HGF cells from different donors showed different ALP levels, and showed that cells preselected with high basal ALP levels demonstrated the ability to mineralize in culture as determined by OCN production and Von Kossa staining while others did not. The HGFs used in our study and in the study by Zhou et al. [15] showed significant ALP levels under normal culture condition which could suggest their inherent osteogenic potential.

The results of our study suggest that under an appropriate conditioning environment (i.e., osteogenic supplementation with an optimal Dex concentration), gingival fibroblasts could be induced into an osteogenic phenotype. The results consistently showed osteogenic effect of Dex on HGF cells to be maximal at 0.1 and $0.5 \mu \mathrm{M}$ Dex, and higher Dex concentrations caused a down regulation of osteogenic effects observed at lower concentrations. A possible explanation for the down-regulation of the osteogenic effect of Dex on HGF at 1 and $10 \mu \mathrm{M}$ is that high Dex concentration increased the population of other cell lineage in the cultured HGF which might explain the reduction in osteogenic potential when Dex concentration was increased beyond $500 \mathrm{nM}$. Therefore, further studies should be performed to better understand and characterize the differentiation of HGF under different conditions. Such suitably modified HGF cells could prove promising for developing cell-based tissue engineering therapies for the regeneration of supporting alveolar bone.

\section{ACKNOWLEDGEMENT}

This research was supported by NSERC I2I project, Fund for Dentistry (Grant \# 2007-08), and a grant from the Faculty of Medicine and Dentistry, University of Alberta, (Grant \# N031000426). The authors would like to thank Professor Dr. Paul Scott for providing the HGF cells. The authors would also like to thank Mrs. Carol Dodd for her technical help.

\section{REFERENCES}

[1] Pihlstrom BL, Michalowicz BS, Johnson NW. Periodontal diseases. Lancet 2005; 366: 1809-20.

[2] Reynolds MA, Aichelmann-Reidy ME, Branch-Mays GL, Gunsolley JC. The efficacy of bone replacement grafts in the treatment of periodontal osseous defects: a systematic review. Ann Periodontol 2003; 8: 227-65.

[3] Needleman IG, Worthington HV, Giedrys-Leeper E, Tucker RJ. Guided tissue regeneration for periodontal infra-bony defects. Cochrane Database Syst Rev 2006: CD001724.

[4] Nakahara T. A review of new developments in tissue engineering therapy for periodontitis. Dent Clin North Am 2006; 50: 265-76, ix-x.

[5] Nanci A, Bosshardt DD. Structure of periodontal tissues in health and disease. Periodontology 2000 2006; 40: 11-28.

[6] Shimabukuro Y, Ichikawa T, Takayama S, et al. Fibroblast growth factor-2 regulates the synthesis of hyaluronan by human periodontal ligament cells. J Cell Physiol 2005; 203: 557-63.

[7] Lallier TE, Spencer A, Fowler MM. Transcript profiling of periodontal fibroblasts and osteoblasts. J Periodontol 2005; 76: 1044-55.

[8] Ivanovski S, Li H, Haase HR, Bartold PM. Expression of bone associated macromolecules by gingival and periodontal ligament fibroblasts. J Periodontal Res 2001; 36: 131-41.

[9] Benatti BB, Silverio KG, Casati MZ, Sallum EA, Nociti FH, Jr. Physiological features of periodontal regeneration and approaches for periodontal tissue engineering utilizing periodontal ligament cells. J Biosci Bioeng 2007; 103: 1-6.

[10] Silva GA, Coutinho OP, Ducheyne P, Reis RL. Materials in particulate form for tissue engineering. 2. Applications in bone. J Tissue Eng Regen Med 2007; 1: 97-109.

[11] Saklatvala J. Glucocorticoids: do we know how they work? Arthritis Res 2002; 4: 146-50.

[12] Kasugai S, Todescan R, Jr., Nagata T, Yao KL, Butler WT, Sodek $\mathrm{J}$. Expression of bone matrix proteins associated with mineralized tissue formation by adult rat bone marrow cells in vitro: inductive effects of dexamethasone on the osteoblastic phenotype. J Cell Physiol 1991; 147: 111-20. 
[13] Arceo N, Sauk JJ, Moehring J, Foster RA, Somerman MJ. Human periodontal cells initiate mineral-like nodules in vitro. J Periodontol 1991; 62: 499-503.

[14] Pi SH, Lee SK, Hwang YS, Choi MG, Lee SK, Kim EC. Differential expression of periodontal ligament-specific markers and osteogenic differentiation in human papilloma virus 16 -immortalized human gingival fibroblasts and periodontal ligament cells. J Periodontal Res 2007; 42: 104-13.

[15] Zhou Y, Hutmacher DW, Sae-Lim V, Zhou Z, Woodruff M, Lim TM. Osteogenic and adipogenic induction potential of human periodontal cells. J Periodontol 2008; 79: 525-34.

[16] Mostafa NZ, Uludag H, Dederich DN, Doschak MR, El-Bialy TH. Anabolic effects of low-intensity pulsed ultrasound on human gingival fibroblasts. Arch Oral Biol 2009; 54: 743-8.

[17] Anderson HC. Mechanism of mineral formation in bone. Lab Invest 1989; 60: 320-30.

[18] Karner E, Unger C, Sloan AJ, Ahrlund-Richter L, Sugars RV, Wendel M. Bone matrix formation in osteogenic cultures derived from human embryonic stem cells in vitro. Stem Cells Dev 2007; 16: $39-52$.

[19] Shimonishi M, Hatakeyama J, Sasano Y, et al. In vitro differentiation of epithelial cells cultured from human periodontal ligament. J Periodontal Res 2007; 42: 456-65.

[20] Lee JH, Rhie JW, Oh DY, Ahn ST. Osteogenic differentiation of human adipose tissue-derived stromal cells (hASCs) in a porous three-dimensional scaffold. Biochem Biophys Res Commun 2008; 370: 456-60.

[21] Varkey M, Kucharski C, Doschak MR, et al. Osteogenic response of bone marrow stromal cells from normal and ovariectomized rats treated with a low dose of basic fibroblast growth factor. Tissue Eng 2007; 13: 809-17.

[22] Polimeni G, Xiropaidis AV, Wikesjo UM. Biology and principles of periodontal wound healing/regeneration. Periodontology 2000 2006; 41: 30-47.

[23] Iwata T, Yamato M, Zhang Z, et al. Validation of human periodontal ligament-derived cells as a reliable source for cytotherapeutic use. j of peridonto 2010; 37(12): 1088-99.

[24] Sandberg MM, Aro HT, Vuorio EI. Gene expression during bone repair. Clin Orthop Relat Res 1993; (289): 292-312.

[25] Haase HR, Ivanovski S, Waters MJ, Bartold PM. Growth hormone regulates osteogenic marker mRNA expression in human periodontal fibroblasts and alveolar bone-derived cells. J Periodontal Res 2003; 38: 366-74.

[26] Pi SH, Lee SK, Hwang YS, Choi MG, Lee SK, Kim EC. Differential expression of periodontal ligament-specific markers and osteogenic differentiation in human papilloma virus 16-immortalized human gingival fibroblasts and periodontal ligament cells. J Periodontal Res 2007; 42(2): 104-13.

[27] Yao KL, Todescan R, Jr., Sodek J. Temporal changes in matrix protein synthesis and mRNA expression during mineralized tissue formation by adult rat bone marrow cells in culture. J Bone Miner Res 1994; 9: 231-40.

[28] Pittenger MF, Mackay AM, Beck SC, et al. Multilineage potential of adult human mesenchymal stem cells. Science 1999; 284: 143-7.

[29] Carnes DL, Maeder CL, Graves DT. Cells with osteoblastic phenotypes can be explanted from human gingiva and periodontal ligament. J Periodontol 1997; 68: 701-7.

(C) Mostafa et al.; Licensee Bentham Open.

This is an open access article licensed under the terms of the Creative Commons Attribution Non-Commercial License (http://creativecommons.org/licenses/by-nc/3.0/) which permits unrestricted, non-commercial use, distribution and reproduction in any medium, provided the work is properly cited. 